Journal of Law \& Social Studies (JLSS)

Volume 3, Issue 1, pp 48-66

www.advancelrf.org

\title{
Terrorism and State Response
}

\author{
Dr. Syed Kaleem Imam \\ Security analyst, former UN Peacekeeper, \\ Inspector General of Police. \\ Email: skimam98@hotmail.com
}

\begin{abstract}
The research aims to examine many elements of terrorism and to represent the difficulties that people encounter as a result of continuing violence. The causes and repercussions of radical ideologies have been highlighted in a detailed analysis of terrorism. The goal of this research is to recognize how violent actions have affected economies, communities, and civilizations both worldwide and locally. Pakistan had to reemerge following the eventual end of terrorism, which was aided by military and police operations carried out in terrorist hotspots and densely populated regions. This paper looked into the root causes of terrorism on a global scale, as well as the consequences of terrorism that have had a significant impact on our country's political, cultural, and economic domains, as well as the historical context of terrorism, as well as the repercussions, aftermath, and critical challenges that the country has faced to date.
\end{abstract}

Keywords: Extremism, violent extremism, radicalization, terrorism, Threat Spectrum, enablers, multipliers, community, State response

\section{Human Existential Nature}

Human behavior must be studied in order to comprehend the idea of extremism. Terrorism and extremism come from an individual's as well as a group's perspective, thus understanding human nature, his views, and their growth is critical. Humans have developed historically from the Stone Age to be hunters, travellers, and farmers, culminating in the modern man that we see today. Humans have been labelled as social animals and logical creatures, but he is essentially an existentialist (Kant), who believes that existence is the most important thing in the world. As a result, he has a tendency to be adamant, adaptable, and willing to disregard moderation in the pursuit of his goals.

Mankind has been biased and prejudiced for millennia, devoted to his ideology above all others, especially his relatives and families, as a result of which he chooses an orthodox path to self-fulfillment. His thoughts have travelled from myths and legends to the fields of rationality, pragmatism, and now science and technology. Humans are mostly concerned with surviving. Self-perpetuations have always been the characteristic of their lives.

\section{Definition of Terrorism}

Terrorism is defined as the use of force, terror, or violence in an unapproved, unlawful, or illegal manner. This negative energy is directed against a specific set of individuals, businesses, religious organizations, governments, political parties, ethnic groupings, and media outlets in order to achieve political, social, and religious objectives. Force is used against the government, powerful organizations, or individuals in order to achieve their goals using politically, economically, or socially motivated means.

Terrorism, for the most part, instills deliberate and determined physical and verbal threats in order to frighten society and authority. This zealous execution of distinct regulations is intended to appease a specific religious, political, or ideological group. Terrorists or criminals create tactics to disrupt the status quo and eliminate a country's or region's current norms by replacing them with their own protocols, values, and knowledge of life. 
Terrorism is a broad term with 212 different definitions. (Simon-1994). Most institutions and industrialized countries, on the other hand, agree on the fundamental notion. Terrorism, according to Georgetown University's Bruce Hoffman, is defined as "violence, or the threat of violence, employed and directed in pursuit of, or service of, a political goal."

Similarly, Oxford University's Louise Richardson argues that terrorism "deliberately and violently targets people for political reasons." When it comes to choosing their targets, terrorists are picky. Non-state actors sometimes attack unarmed individuals, while others choose to strike high-profile officials or high-value targets.

When it comes to the target strategy for terrorists, however, there is no uniform solution because radical groups frequently overpower tiny and large-scale organizations, the vulnerable people, and hard targets. Counter-terrorism is the use of a combination of military, political, social, and economic methods used by local authorities in collaboration with intelligence agencies to battle or eliminate terrorism at various levels.

The term "radicalization" refers to a mentality or process in which an individual or a group of individuals adopts extremist political, social, or religious beliefs. It is the first step toward becoming a terrorist through radicalized ideas and views. The term "de-radicalization" refers to the practice and tactics used to reverse a radicalization process that has already occurred, therefore reducing the danger of terrorism in society.

\section{Extremism}

The process of advocating extreme beliefs in order to carry out first terrorist actions is known as extremism. Fundamentalism, fanaticism, prejudice, and zealotry are all examples of extreme attitudes. It refers to a set of beliefs that differs from the majority of people's beliefs in their culture. As a result, extremist mentalities seek to achieve goals by frightening governments or communities in order to pursue personal aims that are anti-state, anti-government, political, religious, or ideological in nature. Extremism is a global phenomenon that no civilization is immune to. The nature and extent of the problem varies from nation to country, depending on the current stage of their socioeconomic development.

\section{Violent Extremism}

Violent extremism is a term that describes behaviors and ideas that encourage ideologically driven violence in order to achieve socioeconomic and political goals. Violent extremism is defined as the continual use of verbal and physical force, abuse, and weaponry to achieve a purpose.

\section{a) Terrorism and Violent Extremism}

Violent extremism's goal is to agitate the target and create hostile situations that lead to undesirable outcomes. Its long-term goal is to radicalise moderates and gather support for frightening goals.

\section{b) Pull factors of Extremism}

Potential terrorists are attracted by monetary incentives or service in exchange for membership, the promise of adventure or independence, and the certainty of spiritual comforts. Positive media material and sympathy-based messages delivered via social media and the Internet can help to drive terrorists away.

\section{c) Push factors of Extremism}

Marginalization, inequality, discrimination, persecutions, poor literacy, denial of civil rights, environmental, historical, and socioeconomic grievances are all important contributors to terrorism's supremacy. Some of the organisations are politically and socially marginalised, posing a danger to personal and communal identity. Disregarded populations are indoctrinated and brainwashed into seeking vengeance against predetermined conceptions, therefore spreading ideological views through fear.

\section{d) Contextual factors for extremism}

Fragile nations, a lack of rule of law, corruption, and criminality, neglected states of affairs, injustice, and communal cultural tendencies all add to the contextual elements that contribute to extremism..

\section{Terrorism}

Terrorism is defined as the use of purposeful violence for political or religious goals in its widest definition. Extremist attitudes are at the root of the phrases "terrorist" and "terrorism."

"Terrorism is the desecration of human dignity" - (Kjell Magne Bondevik) 


\section{Dynamics of Terrorism}

Terrorism is more prevalent in certain civilizations than in others. Many individuals believe that focusing on primary origins, reasons, and criticisms is associated with condoning violence, therefore discussions regarding the causes of terrorism are controversial. Certain interpretations, however, have pointed to psychological, ideological, and socioeconomic factors as contributing to terrorism.

Terrorism may manifest itself in a number of ways and in different social contexts. Terrorism can be perpetrated by deprived, illiterate, rich, or impoverished people of any gender.

Terrorists encourage violence for a variety of personal motives as well as their present psychological state of mind. They are driven to participate in negativity by a desire for power or some form of indefinite gain. Terrorism may manifest itself in a variety of ways. It is centered on hidden ideologies and religious commitments that expose society to terrorism. To go further, a fair-minded and unbiased perspective is required to comprehend the dynamics at play behind this notion, as this will aid in the development of an effective plan to solve long-term solutions.

The following are the psychological, social, and economic variables that influence the degree of radicalization and deradicalization:

\section{a) Psychological Factors}

In the formation of radicals and extremists, three elements are considered significant.

1- Individual needs that increase political violent participation.

2- The mentality and ideology that promotes political violence.

3- The community protocols and social environment that affect their extremist decision-making.

Terrorist membership and radicalization are more common in people who are furious, outraged, or alienated, according to John Hogan, a researcher at the Pennsylvania State University International Centre for the Study of Terrorism.

They think they are psychologically responsible and allowed to change the present political order. Furthermore, the notion of social movement incentives encourages people to join movements that provide solidarity and companionship to the downtrodden.

\section{b) Social Factors}

Societal factors are defined by the level of life, education, security, political considerations, crime, and governance. Terrorism is more likely in societies that lack these traits, resulting in weak social systems. In general, a society with a varied ethnic population combined with political illegitimacy leads to ideological division. As a result, poverty and inequality reign, exposing disparities and inequalities across culturally separated communities.

\section{c) Economic Factors}

Because of falling job rates, low GDP and GNP (Gross National Happiness), diminished holistic progress, unsustainable development, and increasing inflation, citizens in weak unstable nations are more prone to become prospective terrorists. Market instability, xenophobia, and a loss of tourism as a result of such situations lead to poverty and disadvantaged conditions. As a result, people feel motivated to engage in illegal and aggressive behavior.

\section{Terrorism Trends}

Ethnic diversity, rapid population expansion, political and religious instability, poverty, a never-ending unemployment rate, pervasive injustice, and political status all spawn radical organizations wanting to pursue violence for personal reasons in developing countries.

"Terrorism has evolved into a methodical weapon of a war with no borders and few faces." (Jacques Chirac)

\section{Terrorism in Pakistan: Nature and Dynamics}

Pakistan is a country where terrorism has grown to incredible proportions. This country has been viewed as a conduit for global extremism and a platform for the spread of intercontinental threats. As a result of the perception of 
extremism as a negative force, Pakistan has stayed in the spotlight of numerous discourses concentrating on security risks presented by and in Pakistan.

Since its foundation, our country has inherited a slew of issues that have plagued us for the past 73 years. Pakistan has been an unrecognised victim of widespread extremism that is firmly ingrained in the country's basic fabric.

1- India-Kashmir conflict: The indiscriminate and cruel treatment of Kashmiri residents is inflaming citizens' rage, prompting them to raise their voices passionately.

2- The Durand line border issue with Afghanistan: Another driving force disrupting peace and security in the region is the legal status of the Durand line, which was emphasised in 1893.

However, the fundamental cause of current extremism and terrorism may be traced back to four key events or developments in the past. Two of them are imposed on us from without.

1- After the Soviet invasion of Afghanistan in 1979, three million Afghans were compelled to flee to Pakistan, never to return. Afghan Mujahedeen, regional and international actor engagement in the area, and a perception of the Taliban as both an adversary and an ally were all bi-products of the invasion of Afghanistan. This life-altering tragedy sparked widespread militancy and hatred across the United States. In the years afterwards, a vicious circle of inter-sect inequalities and inequities has replaced this, leading to interfaith confusion.

2- After the terrorist attacks on the Twin Towers in New York City on September 11, 2001, the United States and NATO forces attacked Afghanistan, forcing non-state entities and militant organisations to react by using Pakistani territory. As a result of our geostrategic situation, we have paid a high price and are still not out of the woods.

Internally, there are two primary elements that contribute to terrorism:

1- The support of criminal elements by political, religious, ethnic groups, elites, and vested interests, particularly in Karachi, the interior, and the frontiers, has pushed the city into the category of dangerous locations.

2- Pakistan's internal security issue dates back to the country's inception. Due to poor administration and political instability, nationalist groups have grown in strength. Patronage by hostile agencies for their malicious schemes has been widespread, resulting in adverse agendas.

Politicization of crime and criminalization of politics. As a result, cops, civil servants, and armed forces had to conduct many operations. Terrorists are taking advantage of this chance to undermine the state's internal security and threaten territorial integrity in order to sabotage national interests.

\section{Emergence and Catalyzation of Extremism}

Unfortunately, our nation never had a visionary and selfless leader after Quaid's death, leaving the way open for opportunists and designated parties. As a result, the country has faced several failures and instances of insecurity since its inception. The absence of law enforcement, as well as a weak education system, poverty, foreign funding for border attacks, and the participation of non-state actors, is a problem, while state institutions' halfhearted responses and contradictory policies are an issue that must be addressed for future stability.

Furthermore, moral anger over the suffering of fellow Muslims in the United States and overseas has aided and abetted radicalism. Ethnic tensions, unchecked foreign interference, and separatist movements are all elements that contribute to terrorism in Pakistan.

\section{Manifestation of Extremism}

Extremism can have five various forms, which are as follows:

1- Religion

2- Sectarian

3- Ethnic

4- Class

5- Gender.

Religious, sectarian, and ethnic extremism are violent kinds of extremism, whereas class and gender extremism are socially disruptive. BLA, JSMM, TI, BRA, MQM, and TTP, SSP, LeT, LeJ, Jaish, ISIS, and JuD have all demonstrated violent extremism in politics and religion. 
Table 1

\section{Liner Chart - Number of Sectarian Incidents in Pakistan}

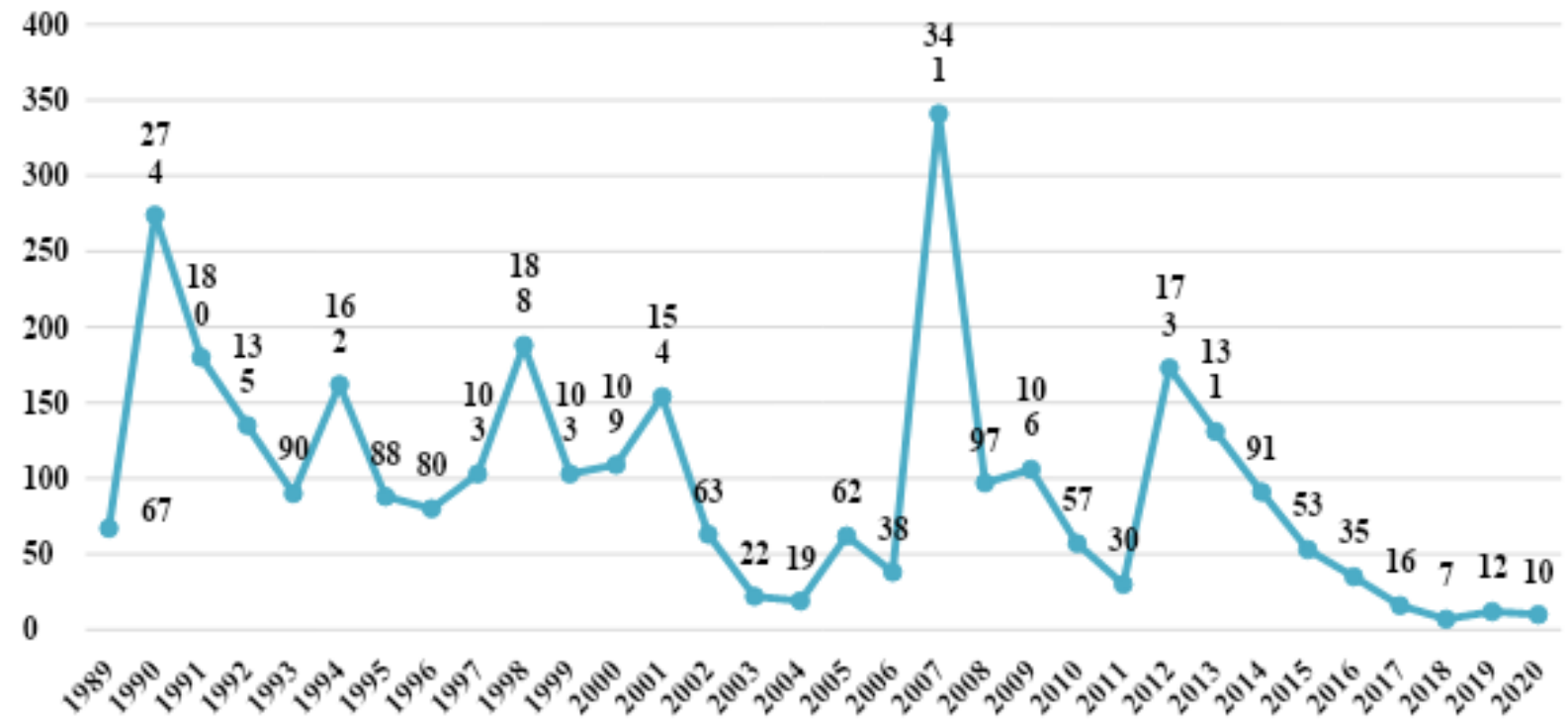

Unstable events began in the late 1980s, according to the linear chart analysis. It began to rise in the early 1990s, with 2007 and 2008 being the worst years. However, as a result of the state's zealous pursuit of its rules, occurrences have decreased substantially. Only two incidences of sectarianism were recorded in February 2021.

Table 2

\section{Bar Chart - Number of Sectarian Casualties in Pakistan}

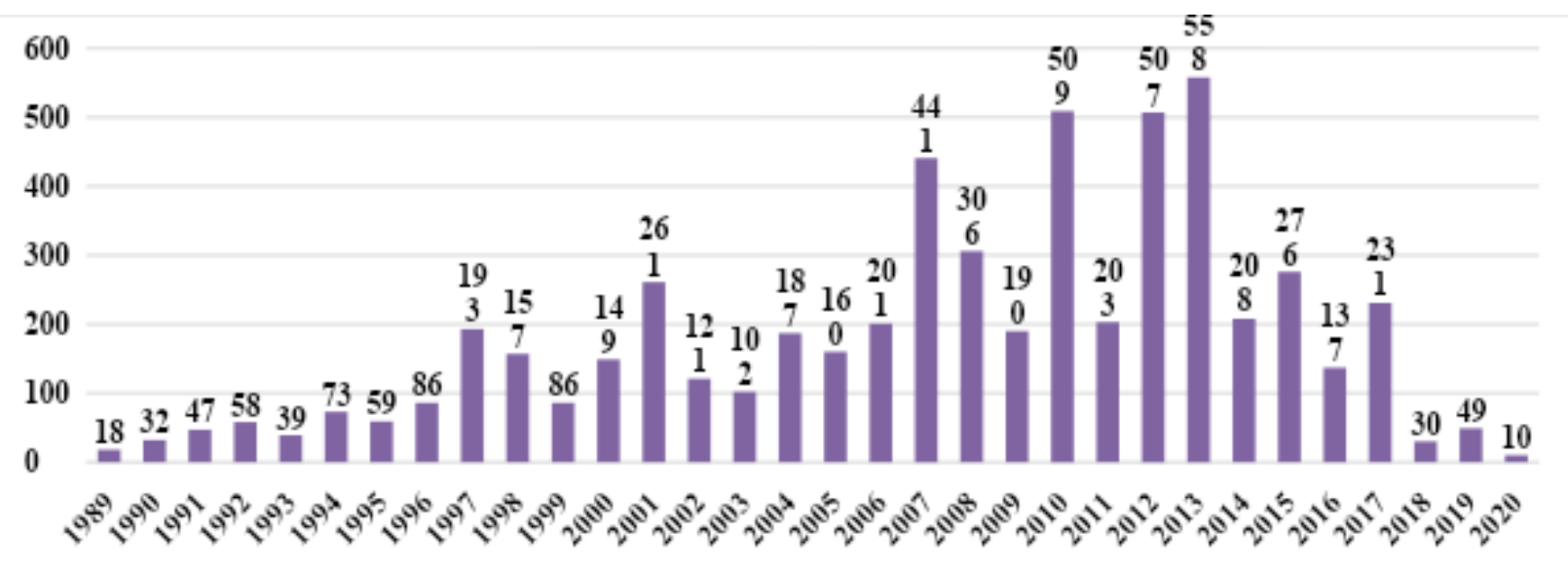

According to a bar chart study, sectarian events rose in the late 1980s. As the death toll increased in the 1990s, the number of casualties began to grow. The worst years were 2007, 2010, 2012, and 2013. The number of sectarian deaths, on the other hand, has decreased, with only two deaths reported in February 2021. The highest number of casualties were recorded in 2013, owing to the political and economic turmoil that characterised those years.

\section{Present threat spectrum}

Threats currently range from indirect to direct, internal to external, conventional to non-traditional, creating complicated security concerns. Our numerous issues may be foreign and forced upon us as a result of our geopolitical circumstances, but recent events show that the adversary is also from inside us. (Lao Tzu)

"In countries where intelligent people are in control, their citizens are unaware of their rulers' existence" - 
Internal dangers now exist as a result of our own erratic policies, political instability, absence of rule of law, and bad governance. Internally, the population is split into four provinces and sub-regions, each with its own culture, language, and customs, creating sectarian and ethnic fault lines that are exploited politically and religiously.

This frequently results in significant law and order issues, organised crime, and violent extremism, which incites sectarianism, terrorism, and militancy with the backing of enemy agencies. Karachi and big cities remained a struggle, while border areas, Sindh's interior, KPK, Baluchistan, and southern Punjab produced a high number of mafias and insurgents, giving rise to separatist and sectarianism movements.

\section{a) External Factors}

Our internal security has been influenced by our geographical positions, regional political events, and international domains. Since independence, the United States has had a tense relationship with India due to ideological disagreements and the unsolved Kashmir problem.

Hegemonistic intentions resulted in harmful acts, particularly along the Eastern and Western frontiers. Infiltrations, smuggling, narcotics, inciting cartels, and supporting rebels in subversive operations have all harmed our reputation both internally and outside.

Militancy and terrorism have emerged in our nation as a result of foreign operations, refugees, non-state actors, and the presence of numerous militants in border areas. Other neighbouring nations have backed sectarian violence fueled by ideology, further radicalising religious and political goals in Pakistan.

\section{b) The emergence of Separatist Movements}

The operations in the region have been impacted by nationalist militancy, particularly in Baluchistan, which is backed by neighbouring nations. The state's exploitation of Baluchistan's resources and its lack of attention to the region's socioeconomic development, according to the dominant narrative, are further causes that have fostered separatist militancy in the province.

The terrorists are gaining financial and emotional power from foreign actors who have meant to harm the country's national security, thus their involvement is clear. Separatist groups have risen as a result of these insurgencies, notably in Sindh and Baluchistan, and are now a serious threat that is steadily increasing its pace and approaching the Metropolitan areas of the country.

This estrangement can be rectified if the people of Baluchistan are convinced that both the federal and provincial governments are working on possible development strategies to bring wealth to this underdeveloped region of the country. Not to mention the fact that the Iranian revolution in 1979 had a significant impact on the scale and intensity of terrorism in Pakistan. The neighbouring revolution sparked sectarianism in Pakistan, which had never been seen before. Sectarian violence and disdain, on the other hand, are today more common than ever. Impact of US Withdrawal in Pakistan

Following the tragic events of 9/11, terroristic actions were uncontrolled. Suicide bombings, targeted assassinations, and other forms of physical violence were commonplace. The American invasion of Afghanistan and military activities within the nation exacerbated such events. The 20 -year-long conflict that US forces started is finally coming to an end. By September 11, 2021, the US military is scheduled to remove its soldiers from Afghanistan.

Instead of calming the situation, foreign invasions in Afghanistan have exacerbated militancy and unpredictability by allowing non-state actors and tiny groups to take control of the hierarchical structure and authority. If the Civil War erupts, we will once again face a massive flood of Afghan migrants, posing a new problem. Non-state actors have received financial and violent training from foreign intelligence services in order to participate in anti-state operations in Pakistan. According to The Washington Quarterly, the CIA, Raw, and Mossad are all involved in obtaining our intelligence and using it for personal advantage.

\section{c) Contextual Factors}

In the recent past, and to a large part in the Fourth Generation Warfare conducted by non-state actors and asymmetric warriors, terrorism was used as a tool to attain political goals, which was both difficult and still poses a threat. Criminals and terrorists use the internet and social media to achieve their illegal aims through diversion, indoctrination, and misinformation, while creating parallel processing hardware and AI (Artificial Intelligence) software in Fifth Generation Warfare. 
The transition from firepower to machine power took 300 years, whereas the transition from machine power to information power took only ten years. The conflict continues, and social media is the new tool of mobilisation. The term "weapons of mass destruction" has been replaced with "weapons of mass disruption."

As a result, the government recently implemented the "removal and blocking of unlawful online content (system, misconceptions, and safeguards) rule 2020" under the Prevention of Electronic Act, which gives the government broad authority to prohibit undesirable digital information.

\section{d) Indicators}

Pakistan's score requires significant improvement as a consequence of external issues such as internal political instability, economic turmoil, and a lack of aggressive law enforcement.

Table 3

Current standing in various indexes is as follows:

\begin{tabular}{|l|l|}
\hline \multicolumn{1}{|c|}{ List of Indicators } & \multicolumn{1}{c|}{ Ranking Among Countries } \\
\hline Human Development Index & 152 out of 189 countries \\
\hline Corruption perception index & 124 out of 180 countries \\
\hline Global Peace Index & 150 out of 168 countries \\
\hline Ease of doing business & 108 out of 188 countries \\
\hline Freedom of Press & 141 out of 201 countries \\
\hline Global competitiveness report & 110 out of 141 countries \\
\hline Global opportunity index & 119 out of 147 countries \\
\hline Global hunger index & 88 out of 107 countries \\
\hline
\end{tabular}

Among the 133 nations in the Southern Asia Safety Index, we are placed 67th in terms of safety and crime.

\section{e) Militant Groups active in the vicinity}

Some of the local groups that are a danger to stability and a source of extremism and terrorism include:

1- Molvi Haibatullah is in charge of the TTA.

2- Noor Wali Mehsud is the leader of the TTP.

3- The TTP's faction is led by Hafiz Gul Bahadur.

4- Muhammad Said Abdul Rehman Al Maula Al Qureshi is the Amir of ISIS (who claim the succession of Baghdadi)

5- Shahab Al Muhajir is the leader of the ISKP.

6- Osama Mahmood is the leader of AQIS in Afghanistan.

7- $\quad$ Aiman Al Zawahiri, the AQ leader

8- Abdul wali@ Khalid Omar Khurasani, Jamatul Ahrar (JUA)

9- Mukarram Mohmand alias Omar Khuransi, HizbulAhrara (HUA)

10- Lashkar e Islam (LI) - Zela Khan Afridi (Previously headed by Mangal Bagh who had died recently).

\section{Impact on Developments}

In the economic, political, and social sectors, the country became the hub of violence, extremism, and turmoil. For more than two decades, militancy has been a defining aspect of Pakistan's extremist and terrorist environment. 
Terrorist actions that began in the 1980s and intensified after 9/11 wreaked havoc in urban, rural, and tribal regions, shocking the nation and its community-like governmental structure.

The never-ending stream of suicide bombings resulted in numerous lives lost and financial damages that are still being addressed. Unfortunately, from the start of the Soviet-Afghan war, inhabitants have been subjected to a barrage of terrorist attacks, severely crippling state infrastructure and the national economy.

The socio-economic characteristics and progress had already been drawn out for a long time, but Pakistan was dealt a serious blow as a result of terrorism. Around 21,672 Pakistani civilians and 2,795 military have died as a result of the conflict. Over these 10 crucial years, the economy was severely harmed, with a loss of about 68 billion dollars.

Our country also paid a high price in the post-recovery era, but certain places, such as Fata and KPK, are still the most hit. The tribal regions have been harmed, as have the primary revenue and capital creation sources. Agriculture, tourism, cottage businesses, and large-scale manufacturing will require a long period of time to recover from this economic shock. Landowners, farmers, and labourers who rely on agriculture for a living demand government financial help and recompense.

Due to the dramatic drop in GDP, the northern districts that serve as the entrance to tourism were shattered, resulting in the loss of a major percentage of revenue and capital. Attacks on educational institutions, public gatherings, and security institutions, as well as suicide bombings, mass target attacks, IED explosions, high-profile celebrity killings, and attacks on educational institutions, public gatherings, and security institutions, have all become major challenges.

\section{a) Social impact}

Trade and commercial operations were halted, which had a negative impact on normal social connections. Unfavorable effects were seen in the labour market, poverty, and infrastructure, all of which resulted in significant human costs. Social gatherings, gatherings, and schooling were all put on hold. The majority of Pakistanis were left homeless, jobless, crippled, and with long-term health issues.

Terrorism lowers job prospects, according to Greenbaum, Dugan, and LaFree's study of the influence on employment and business outcomes in Italy from 1985 to 1997. Because it affects people's lives, employment is more of a social issue than an economic one. The unemployment rate rose from 3.12 million in 2009-10 to 3.40 million in 2010-11 as a result. However, by 2020, the number will have risen dramatically to 6.65 million. The unemployment rate for the coming year (2020-21) has been predicted at 9.56 percent, according to the Labour Force Survey 2017-18.

Local businesses were also disrupted by the relocation of people, notably during the Swat conflict. To immobilise the young, schools and academic institutes were targeted for halting academic events.

Militants attacked 758 schools across the province, including 640 schools in the Malakand division, according to the KPK Education Department. Furthermore, the leisure and entertainment business came to a halt, and culture as a whole was disturbed.

\section{b) Political turmoil}

The country was thrust back into a period of unparalleled insecurity, instability, and complication. The Frontier Crime Regulation (FCR) and Jirgas, which operate in collaboration with political negotiators planned by the government, carry out the majority of political and judicial judgments. During the crisis, these figures were targeted, disrupting the tribal area's political equilibrium.

The country's political parties were further split, altering politics and generating more disruptions and difficulties inside the country. During these globalised times, the unexpected political upheaval also left us isolated. As a result, we needed to improve our political position and gain the trust of industrialized countries and their governments in order to improve political affairs and improve our worldwide standing.

\section{c) Economic impact}

During the previous 17 years of post-9/11 counterterrorism scenarios, our economy has lost roughly $\$ 126.79$ billion. Normal commerce and commercial activities were disrupted, resulting in significant economic losses for the country. In terms of foreign trade, it too suffered a setback. After losing market share as a result of frequent terrorist assaults throughout the boom years, the country is still unhinged. Terrorism has had a negative impact on foreign investment, tax collection, and significant export goods. Pakistan suffered not just financial and economic losses, but also a loss of human capital. 


\section{d) Community Response}

The general public began to respond by assisting law enforcement authorities and telling them of criminal activity, gathering and sharing information, and alerting via levels of family, neighbour, and locality knowledge. Committees, such as peace committees, as well as rescue and relief groups, were created. 1122 Edhi, CHIPPA, CPLC. Rescue 15, as well as women's and children's protection forums and task teams, are gaining traction in the fight against crime and providing relief to victims.

\section{e) Government Response}

Counter-Terrorism Departments (CTD) were established at the federal level. The CIA was improved in a number of locations, the special branch was beefed up, elites were recruited, ATF training began, and a lot of collaboration between various law enforcement organisations began. The emphasis moved to specialisation, technology-assisted labour, and the collecting of crime data. Special Forces are raised, and various national and international training programmes are underway. K9 units, bomb disposal, forensics, software, and computer surveillance have all been improved. According to counterterrorism programmes, governmental responses may be divided into three categories: legal, military, and executive. A variety of initiatives have been made in the framework of executive and legal measures to combat the threat of terrorism. However, the achievements made in counter-terrorism can only be strengthened by focusing on structural changes, as outlined in the National Action Plan.

\section{i. National Counter Terrorism Authority}

A concerted effort was made at the legal and policy level to strengthen the criminal justice response to terrorism. The National Counter Terrorism Authority (NACTA) was established in 2013 under the National Counter Terrorism Authority Act, with the mission of addressing short, medium, and long-term counter-terrorism measures.

Its main task was to gather and provide intelligence to various institutions and agencies in order to create threat assessments for the Federal Government. This was started in order to design and implement a comprehensive counterterrorism strategy that would combine and integrate governmental reaction to and grassroots initiatives by creating and executing actions and strategies based on ongoing reforms and research.

\section{ii. National Action Plan}

The National Action Plan (NAP) was the first methodical reaction, followed by the creation of the National Internal Security Policy (NISP). It primarily consisted of three main groups of measures: interim, kinetic, and non-kinetic.

It was written in the aftermath of the Peshawar school assault, a tragic and horrific slaughter that ripped innocent lives apart. The National Action Plan (NAP) was created by the government in 2014 as a collective response to a huge crackdown on terrorism, and it supports anti-terrorist activities throughout the Federally Administered Tribal Areas (FATA).

The NAP included local and international efforts, as well as alternatives, that garnered enthusiastic support and extraordinary praise from the federal and provincial governments. The elimination of prohibited groups functioning across the country was aimed under this initiative. This strategy served as the foundation for Pakistan's 21 st amendment to the constitution, which favoured speedy trials in military tribunals, particularly in cases involving terrorism.

\section{iii. Legislations}

There were two important legislation that emerged:

1- The Investigation for Fair Trial Act 2013

2- Protection of Pakistan Act 2014.

These regulations sought to make counter-terrorist measures more realistic by emphasising the significance of assessing and evaluating terrorism situations. As a result, it aided the country's conviction rate for terrorism-related crimes.

To combat extremism and acts of terrorism, the following laws are now in effect.

1- Suppression of Terrorists Act 1975

2- Anti-Terrorism Act 1997

3- Regulations Action in Aid of Civil Powers 2011 
4- Punjab Protection of Vulnerable Persons Rules 2015

5- Prevention of Electronic Crimes Act 2016

By establishing an anti-terrorism law framework to combat extremist activity in the country, the government was able to portray a positive image and define its reputation. The Anti-Terrorism Act of 1997, as well as Pakistan's Penal Code, punishes criminal actions, notably violence against the state, which is often associated with acts of extremism.

\section{iv. National Internal Security Policy}

Following that, from 2014 and 2018, the National Internal Security Policy (NISP) allowed for a magnificent combination of hard and soft state measures in response to problems posed by militancy to the state and society. CRP and CDP are the two main components of NISP. Comprehensive Response Plan (CRP)

It is intended for softer interventions and includes the following:

1- It emphasizes the development of a common narrative against terrorism and extremism that leads to national de-radicalization programmes and settlement among the many actors/groups involved.

2- The strategy aims for broad political advancements, popular support against extremism, dialogue-based sponsorship, the return of displaced individuals, socioeconomic development, and fundamental reorganization.

3- It encourages kids to participate in healthy activities and integrates religious institutions into the educational system.

4- The soft intervention includes interaction with stakeholders in order to build a national narrative and society's socioeconomic growth.

5- Equality, peace, and justice may be achieved via democratic involvement and the presence of trust between local communities and the state. Combating radicalization on a broad scale in order to aid community development and minimise social divisions, which have been identified as a major cause in large-scale divisions.

6- Practical and efficient communication channels, including religious establishments and Islamic schools, that strive to bridge the gap between state and local communities and authorities as a preventative step.

\section{a) Composite Deterrence Plan (CDP):}

It is still seen as the negative side of government action.

1- It focuses on strengthening the National Internal Security Apparatus (NISA) and establishing an arms control administration.

2- It proposes the creation of a national database, as well as operational measures, to provide a safety net against cybercrime.

3- Establishment of a Directorate of Internal Security (DIS) to coordinate intelligence-based activities, as well as steps to restore and control Afghan refugees.

4- In addition to the creation of a Rapid Response Force and a Counter-Terrorism Department, law enforcement agencies needed to be completely overhauled and renovated. To scale the national security apparatus, modernization of the organisational structure and agencies is required.

\section{v. Operational Plans - Law Enforcement Agencies}

The action plan has evolved in three unique ways in the past:

1- Tackling and outlawing violent, extremist groups that engage in anti-state actions.

2- Monitoring particular organisations and individuals so that they cannot change their names and function in the nation again.

3- Taking action against them based on information, search and sweep operations, and displacement of such elements from formal tribal regions, central districts in KPK, Sindh, and Punjab.

Counter-terrorism actions spearheaded by the military were a tremendous success. The military actions, as well as their time span and areas, are listed in the table below.

Table 7

Linear Chart - Number of Counter-Terrorism Military Operations in Pakistan 


\begin{tabular}{|l|c|l|}
\hline \multicolumn{1}{|c|}{ Operation } & \multicolumn{1}{|c|}{ Period } & \multicolumn{1}{c|}{ Target Area } \\
\hline Al-Mizan & $2002-06$ & FATA \\
\hline Rah-e-Haq & 2007 & Swat \\
\hline Sher-e-Dil & 2008 & Bajaur Agency \\
\hline Zalzala & 2008 & South Waziristan \\
\hline Sirat-e-Mustaqeem & 2008 & Khyber Agency \\
\hline Rah-e-Raast & 2009 & Swat \\
\hline Rah-e-Nijaat & 2009 & South Waziristan \\
\hline Koh-e-Sufaid & 2011 & Kurram Agency \\
\hline Zarb-e-Azb & 2014 & Across Pakistan \\
\hline Radd-ul-Fasad & 2017 & Across Pakistan \\
\hline
\end{tabular}

In terms of counterterrorism, operations Zarb-e-Azb and Radd-ul-Fasaad are more thorough and result-oriented.

\section{vi. National Internal Security Policy 2018-2023, has a 6-R strategy}

The new NISP shifted away from CRP and CDP and toward a 6-R approach, which includes:

1- Re-imagine

2- Reconcile

3- Redistribute

4- Recognize

5- Regional approach and

6- Reorient facets of the state and how it interfaces with its citizens.

\section{f) Foreign Response}

The suppression of terrorist networks and operations was aided by several Muslim nations and organisations. More than 50 cases of hard-core and well-known terrorists were convicted and executed in military tribunals as a result of this activity.

Table 4

\section{Linear Chart - Number of Terrorist Acts in Pakistan}




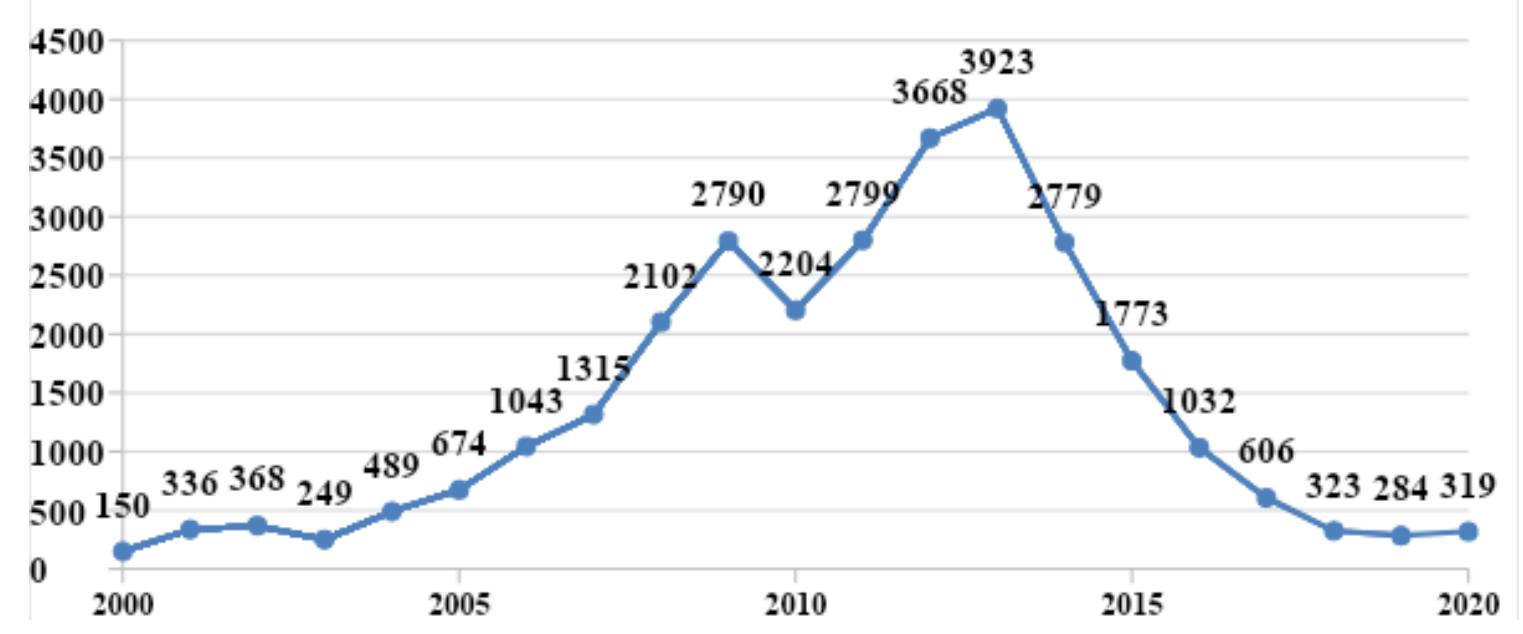

Terrorist attacks increased dramatically from 2005 to 2013, however as a consequence of counterterrorism strategies and military efforts, casualties and incidents decreased considerably.

Table 5

Linear Chart - Number of Suicide Attacks Incidents in Pakistan

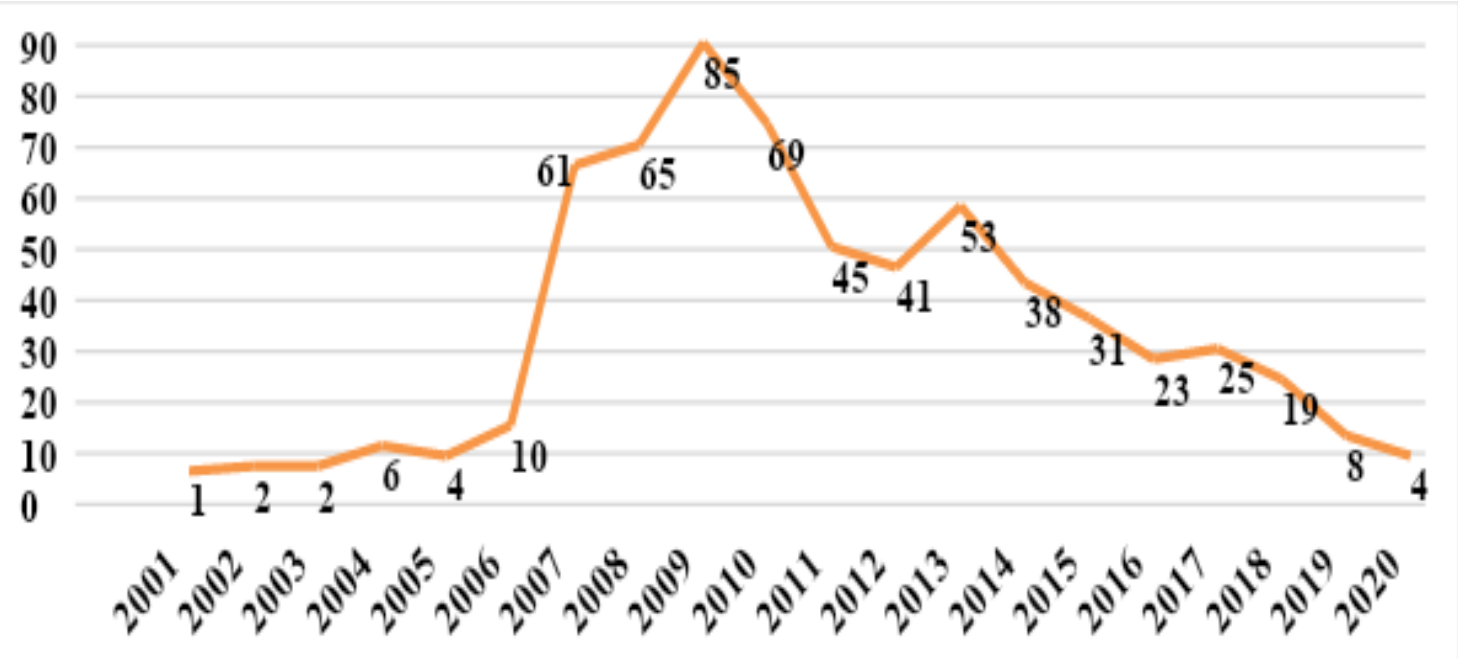

Between 2007 and 2009, there was a significant increase in suicide occurrences, although the total number of suicide attacks decreased, owing to a crackdown in local academic institutions such as Madrasahs.

Table 6

Linear Chart - Number of Suicide Attacks causalities in Pakistan 


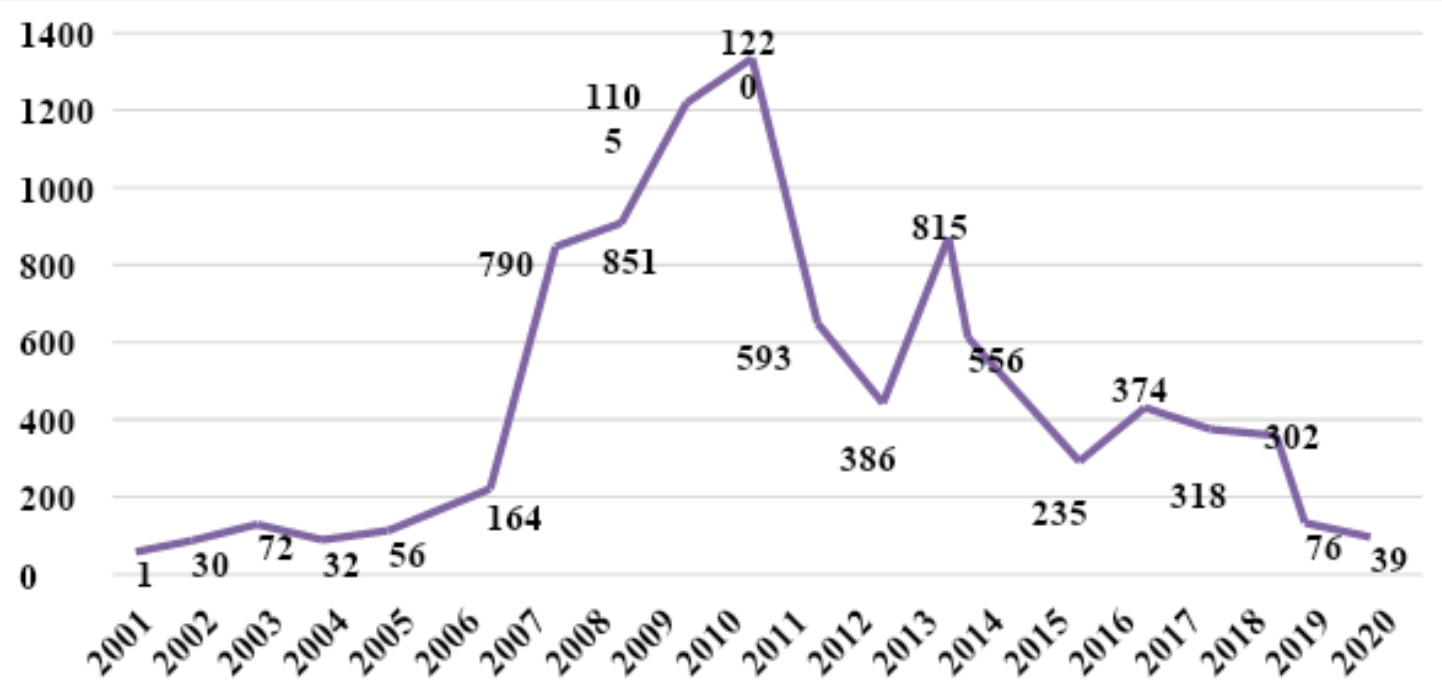

From 2006 to 2016, the number of people killed or injured as a consequence of suicide attacks increased dramatically. It took a break following the NAP and the implementation of the NISP.

\section{Issues and Challenges}

The following are some of the difficulties and challenges that have arisen as a result of terrorism and extremism.

\section{Government Induced Initiatives}

Since 1997, the Anti-Terrorism Act has been used to manipulate electoral outcomes. The original anti-terrorism statute needs to be updated for greater reinforcement. ATA was previously renewed, but it still has to be strengthened, notably in the criminal justice response to terrorism. To tackle the failures of trials, the international human rights community has to address the lack of correspondence of the Anti-Terrorist Act (ATA). Effectiveness can only be accomplished if the government takes legal and policy steps to draw attention to the problem.

In addition, the Ministry of Interior (MOI) created 14 expert groups, the recommendations of which have yet to be implemented. The NISP is governed by the MOI, which mandates that the counter-terrorism plan's responsibilities and accountability be distributed across governmental bodies, including the Federal and Provincial governments.

\section{Global Regulations}

Despite "substantial progress," the Financial Action Task Force (FATF) stated on February 22, 2021 that Pakistan will remain on the grey list of "High-risk countries subject to a request for Action" until June 2021. Pakistan will also need to pass legislation on at least two counts in order to fulfil the FATF's three unresolved 27-point criteria. In the last year, the government has passed three dozen legislation in order to fulfil the FATF's requirements. According to a study paper produced by Tabadlab, an independent think group, Pakistan has lost $\$ 38$ billion as a result of its inclusion on the grey list.

\section{Digital Challenges}


Cyber Terrorism or Cyber Warfare by hostile agencies or non-state actors continues to frighten Pakistan by conducting a computer-based attack against our systems, networks, or the information stored on them in order to further their political or ideological aims. Cyber espionage, money theft, and other trans-border crimes are all examples of this.

\section{Executive Decisions}

After the Swat campaign against the Taliban in September 2009, armed forces launched their first deradicalization programme. Around 2500-3000 Taliban were reportedly deradicalized and reformed. These were known as De-Radicalization and Emancipation Programs, or DREPs, and included Rastoon, Sabaoon, and Mishal.

In Punjab, the Counter Terrorism Department CTD Punjab and the Technical Education and Vocational Training Authority (TEVTA) launched a programme in 2011, however it was cancelled in 2012 owing to a lack of finances and some poor reports. The main issue is that attempts to de-radicalize are unmatched/insignificant in the light of the huge challenge of increasing extremism/violent extremism.

\section{De Radicalization and Counterterrorism suggested Models}

A complete 4D strategy is necessary to strategize de-radicalization: Democracy, Dialogue, Development, and Deterrence at the state level in order to build a better political, economic, educational, and law enforcement environment.

\section{Understanding Root Cause}

It's crucial to understand how the idea of "validation and invalidation" is transformed by the "personal construct theory." Radicalization only occurs when a person feels invalidated, leading to the adoption of new radicalised roles and views. Individuals seeking confirmation for their shaky views and beliefs frequently join the bandwagon.

As the snowball effect grows, there is a visible repulsion and the formation of unfavourable opinions about another group or community, which leads to extremism. Aside from practical solutions, understanding the beliefs, early experiences, and ambiguous attitudes that lead to extremism is critical.

In collaboration with health and psychiatric services, police/CTD must gather data, establish classifications, and implement de-radicalization programmes. Deradicalization is only feasible if realistic steps and preventative tactics are implemented, with a special focus on each individual's attitude.

\section{Ownership of Disenfranchised}

People's perceptions of the state must be developed, particularly in tribal and interior areas. Their problems and concerns, including religious sensitivities, must be addressed, handled, and accommodated within a dialogue and accommodation framework. Instead of the existing stratification and isolation, engagement and inclusion without the "us" and "them" attitude will generate social homogeneity and cohesion. The government should meet people's basic necessities while also safeguarding their human dignity.

\section{Reviewing Sentencing Regime}

Pakistan should reform its consecutive sentence policy. Even the most heinous crimes are resolved, and inmates are released after a period of time. To improve its counter-terrorism operations, our country need a useful and effective punishment framework. Other realistic solutions should be developed that function as a strong deterrence in high-level offences. Furthermore, in order to avoid relapses, recovered persons must be helped in becoming valuable members of society through meaningful work and subsequent feedback. Pakistan's legal efforts to combat radicalization at the grassroots level have evolved over time. They are also pursuing sectarian unification and concord, as well as anti-radicalization efforts.

\section{Revamping State Retaliation Programs}

As a first step, the NAP and NISP should be updated. Counter-narrative development, de-radicalization of impacted persons, and control over the flow of cash and weapons to such groups must all be part of the strategy and plan. To fulfil NAP's goals, this involves modernising and strengthening the criminal justice system.

The perpetuation, promotion, protection, and sponsorship of radical narratives and ideologies by anybody is a serious problem. As a result, in order to combat the extremism threat, the government should prohibit such organisations from sponsoring extremism and violence. 


\section{Streamlining Madrasah Culture}

Madrassahs are well-known for their role in instilling Islamic beliefs and teachings in young people. During the peak years of terrorism, 2006 to 2016, they were seen to play a role that was contradictory to their initial responsibilities. Some professors, clerics, and a limited number of Madrasas have formed alliances with radical organisations, rejecting Western concepts and beliefs in favour of extreme views and opposition to the current administration.

The religious seminary system should be updated. Their curriculum needs to be updated. It is necessary to develop a criterion for selecting professors. Their finances should be audited and they should be paid by the government. Jihadi music and statements should also be prohibited.

Ulemas with more access to vulnerable areas should be involved by fostering trust and developing transformative initiatives to deter kids from joining extremist groups. Another component is to raise the profile of religious leaders who speak out against violent extremism, such as the Paigham-i-Pakistan Fatwa. The local police must have information on all Madrassa students in their jurisdiction, as well as thorough information on their family backgrounds. It is critical to have police verification followed by frequent inspections from the local authorities.

\section{Renewing Education Sector}

Object to the government's rising religiosity, which includes the prohibition of academic publications on Islamic history, the teaching of obligatory Arabic, and the introduction of mandatory Quranic study with translation at the university level. Such efforts, which are taken for political reasons, are ineffective and exacerbate the religious gap.

De-radicalization can be greatly aided by education harmonisation. It is only feasible if we have a state-run, unified education system. Education instils civic awareness, as well as a patient and tolerant community. From elementary through graduate school, high-quality education should be available, and significant inequities in the education sector should be addressed.

Students should be exposed to a diverse range of disciplines, including sciences, sports, and the arts, in order to develop collaboration and vocational skills. If public institutions are updated and cheap education is provided, the number of young people admitted to questionable and mysterious groups promoting extreme ideas would decrease.

\section{The Role of Law Enforcement}

Police have the essential on-the-ground knowledge and a robust network of qualified officers who can distinguish the section in which a person is treading. Because of their grassroots outreach, the police have the ability to monitor extremist elements. At the local level, the police have access to information and act as a convenient link between security services, local government structures, and state organisations. As a result, the police are in a perfect position to lead a multi-agency response against radicalization.

The police can also play a significant role in community-based programmes aimed at reducing radicalization in society. The government may successfully undertake de-radicalization initiatives in vulnerable regions and communities by actively engaging community leaders, civil society groups, and police, including female community leaders. The importance of engaging with people and the public is shown by the fact that police may positively employ first-hand knowledge supplied by individuals to tackle it successfully.

\section{Improving law and order}

To eliminate mistrust, suspicion, and hesitancy between law enforcement and the general public, police should develop a citizen-oriented approach. The police department may prevent terrorist activities and assaults by responding quickly, making themselves accessible to the public, and acknowledging citizen demands.

Police can have an indirect role in implementing anti-hate and anti-provocative material legislation, particularly on social media. Within the police force, it is critical to create a framework for recognising dangers connected with extremism and radicalization. A training facility might also be proposed.

Police leadership must deal with enthusiasm, improve their capacity, groom their subordinates, offer resources, create an environment, demonstrate will, diligence and devotion, establish and sustain excellent practises, innovate, and cooperate activities using other tested best practises. 


\section{Well-designed Foreign Policy}

Foreign policy aids diplomatic resolution of difficulties. Because terrorism takes a multifaceted strategy, foreign involvement must be acknowledged and detected. Radicalization can be eliminated across the country if the local and global elements are considered. Other players' financial, logistical, and weaponry assistance for militants should be recognised. Similarly, regional or trans-regional coalitions can help to build support and balance within an area. As a result, we may still improve our international standing by pursuing an active and aggressive foreign policy.

\section{Administrative Reforms}

Without a comprehensive and broad de-radicalization programme, no counter-terrorism strategy can be successful in the long run. The district administration and its many departments should be included in such a de-radicalization campaign, which may undoubtedly be led by the District Police in collaboration with CTD, sister agencies, and other sectors of society.

A functionally specialised Community Policing Unit can be created at the district level for this purpose. Such a unit would devise a complete strategy that could be put into action. The unit would not only seek to de-radicalize the individual, but also to help him or her reintegrate into society as a regular person. Furthermore, in collaboration with the District Security Branch, CTD, and others, the same unit might be entrusted with the individual's monitoring in the future. Through awareness initiatives, seminars, media platforms, and rallies, this unit may collaborate with the religious sector, teachers, and civil society to promote a more tolerant society.

\section{Role of Media}

As a single platform that connects people of various origins and interests, the media must play its proper role in combating extreme beliefs and views. The media may be used to spread information and rally people to oppose violence collectively. Rather than focusing on individual aims, national security should be prioritised, and terrorist acts should be discouraged.

\section{Inculcation of Technology}

Technology, forensic science, and collaborations with intelligence agencies, other law enforcement departments, and private stakeholders such as community and info-techs, bio-techs, (International UNO and INTERPOL) might be helpful in de-radicalization and counter-terrorism.

Terrorist operations such as finance collecting, communication, provocation, training, armament, preparation, planning, strategizing, and recruiting are all made easier by the internet and social media platforms. Terrorists and possible violent actions should be tracked and located, which may be done with the use of high-tech, stateof-the-art digital gadgets.

\section{Strengthening Civil Societies}

Pakistan's civil society groups should play a distinct role in addressing the various communities and launching unification programs based on trust and resilience. CS should advocate counterterrorism through rallies, seminars, conferences, and the media, starting at the most basic levels and progressing to the largest communities. These organisations should promote for social consistency and inter-ethnic and cultural harmony on an individual, religious, and societal level. Currently, there are six recognised deradicalization programmes in Pakistan, with militants being rehabilitated in Sabawoon (dawn light), Mishal, Sparley, Rastoon, Pythom, and Heila.

\section{Recommendations}

It is difficult for police to carry out a de-radicalization campaign on their own due to a lack of resources and ability. However, police can play a role in the following areas as part of a well-designed programme:

1- Identifying possible deradicalization candidates

2- Dismantling the link between criminality and militancy

3- Individuals who have been reintegrated are being watched and monitored.

4- Community engagement strengthens the role of civil society organisations and other stakeholders. 
5- As a responsible pillar of the society, the police should begin efforts to minimise corruption and enhance efficacy by establishing a hierarchical structure.

6- To alleviate poverty at the grassroots level, the government should implement effective and constructive job programs.

7- Extremist militants should be given an opportunity to mediate and achieve their goals via diplomacy and discussion.

8- To combat terrorism, media outlets across the country should conduct responsible reporting and journalism.

\section{Present dichotomies}

There appears to be more than one theory and contrasts for defining and responding to terrorism. It is believed that terrorism is the existence of possible tension as well as the interdependence of the international actors and domestic players. This topic of concern has been highlighted in the debate of terrorism along with mounting incongruities on whether terrorists should be prosecuted before the international constructed tribunals or national courts.

Moreover, terrorism needs to be addressed as the problem of peace. The correction of the problem ought to be improved through law enforcement or the presence of domestic criminal law and anti-terrorism schemes. Previously, terrorism was considered as a problem of war containing significant use of force and ammunition disturbing the international humanitarian law.

There have been ongoing deliberations about the nature of terrorism whether it is political or legal. Political experts believe that to counter, force is monitored and regulated at the international sphere through the presence of voluntary corporation of nations and other factors such as the organizational structure of the international legal order and the pacific tendencies of nation-states.

Some of the experts argue that peace and law have little or no association with each other and to presume so would be entirely utopian. Different policy experts such as Richard Perle and Donald Rumsfeld have suppressed the significance of legal solutions to the existing problems of world order. They believe that politics is purely predominant and power is deep-rooted.

This concern gives rise to questions regarding the nature of terrorism and mentions concepts hidden under the lines. Deeper dilemmas such as whether terrorism should be viewed as a problem of law (domestic or criminal) or merely a condition achieved through power and practicality have been highlighted.

Lastly, the definition of terrorism has been identified as the presence of state-sponsored initiatives by multiple non-state actors or an amalgamation of state and non-state actors such as the Afghanistan model.

\section{Conclusion}

In response to terrorism, the prevailing breaches should be addressed. The following should be supervised as a policy for further expansion approaches.

1- The presence of domestic and international criminal regulation and enforcement.

2- The existing gap and contrast (dichotomy) between the historical evolution of terrorism in war and peace.

3- Legal solutions to terrorism and the strategies contained in remodeling through direct action and force.

4- The labeling of terrorism as state or non-state accountability.

We urgently require more time to reclaim our status as a peaceful nation. Nonetheless, by honouring sacrifices and combating the societal threat, we have been able to ward off terrorist operations and delinquents. Not only the government, but people as well, must take steps to build a peaceful Islamic culture and for our country to promote the notion of kindness, reflect positive role models, and demolish stereotypes.

Terrorism must be destroyed because it stands in the way of achieving socioeconomic development, political balance, and geostrategic stability. Achievements and milestones in development can only be achieved without the use of violence or weaponry. Achievements and milestones in development can only be achieved without the use of violence or weaponry. If different paths are pursued locally and globally, our country can become a 
progressive society. We must strive for a comprehensive strategy that promotes diverse culture, tolerance, and a peaceful, corruption-free society.

\section{Reference}

Simon, Jeffrey D. (1994). The Terrorist Trap. Bloomington: Indiana University Press.

Antonia Ward (June 4, 2018) An analyst in the Defence, Security, and Infrastructure Research Group at RAND Europe.

B.Lia, K Skjolberg (2004) Causes of Terrorism: An Expanded and Updated Review of the Literature.

Annual Threat Assessment of the US Threat Assessment Community (April 09, 2021)

The Longford Journal, Feb 10, 2017.

Anju Gupta, (May 24, 2021), Afghanistan 2.0: What continued US engagement means for the region.

Syed Mohammad Ali, Muhammad Asad Rafi, Mosharraf Zaidi, (February ,2021), PAK-AMERICANA Ushering in a New Era for Pakistan-US Relations

Ejaz Hussain and Muhammad Jahanzaib, (November 2015), Afghanistan: The Western Withdrawal and its Implications for Security and Economy

National Internal Security Policy, 2014-2018, National Counter Terrorism Authority (NACTA)

National Internal Security Policy, 2018-2023, National Counter Terrorism Authority (NACTA)

Pakistan Monthly Extreme Watch, (April 2021) Compiled by National Initiative against Organized Crime (NIOC)

National Initiative against Organized Crime (NIOC) Newsletter, (March 2021)

National Action Plan (NAP), (2014), National Counter Terrorism Authority (NACTA)

Ministry of Finance, Govt. of Pakistan, “Economic survey of Pakistan”. http://www.finance.gov.pk/poverty/PRSPII.pdf.

The Express Tribune, "Over 3,000 schools destroyed in militancy, disasters: official" https://tribune.com.pk/story/393911/over-3000-\%20schools-destroyed-in-militancy-disasters-official

Pakistan Institute of Peace Studies, "Pakistan security report -2010"

http://san-pips.com/download.php?f=74.pdf

Muhammad Irshad, "Terrorism in Pakistan: causes and remedies". The Dialogue, 6 no. 3(2011): 223-241.

Basit, Abdul. "Countering Violent Extremism: Evaluating Pakistan's Counter-Radicalization and de-Radicalization Initiatives.” IPRI Journal 15, no.2 (2015): 44-68

Schmid, Alex P. Radicalisation, De-Radicalisation, Counter-Radicalisation: A Conceptual Discussion and Literature Review. ICCT Research Paper, (2013).

Clark McCauley and Sophia Moskalenko. "Mechanisms of Political Radicalization: Pathways Toward Terrorism", Terrorism and Political Violence, 20:3, (2008), pp.415-433.

Borum, Randy. "Understanding the Terrorist Mind-Set", FBI Law Enforcement Bulletin, 72:7, (2003), pp. 7-10.

lark McCauley and Sophia Moskalenko. "Mechanisms of Political Radicalization: Pathways Toward Terrorism", Terrorism and Political Violence, 20:3, (2008), pp.415-433.

Wiktorowicz, Quintan. "Joining the Cause: Al-Muhajiroun and Radical Islam", The Roots of Radical Islam, Department of International Studies, Rhodes College, (2004).

Ethan Bueno de Mesquita C. Christine Fair Jenna Jordan Rasul Bakhsh Rais Jacob N. Shapirot Measuring Political Violence in Pakistan: Insights from the BFRS Dataset.

Joseph K. Young, Michael G. Findley - Promise and Pitfalls of Terrorism Research, "What does Radicalization Look Like? Four Visualisations of Socialisation into Violent Extremism" - Diego Muro, Lecturer in International Relations, University of St Andrews and Associate Senior Researcher, CIDOB 
Andrew Silke "An Introduction to Terrorism Research".

Rohan Gunaratna and Mohd Mizan Aslam - "Civil Society Organizations Against Terrorism Case Studies from Asia" Edited by the authors.

Fariha Sami and Munir Khan Khattak - "The Impact of Terrorism on the Economic Growth: An Empirical Study of Pakistan": The Journal of Humanities and Social.

Isabel Green Jonegård "The Implications of a US withdrawal from Afghanistan Four scenarios"

The daily DAWN "Number of jobless people to reach $6.65 \mathrm{~m}$ in 2020-21" https://www.dawn.com/news/1564053 